\title{
Automatic Generation Control of Multigeneration Power System
}

\author{
Asma Aziz, Amanullah Mto, Alex Stojsevski \\ Faculty of Science, Engineering and Built Environment Deakin University Geelong, Geelong, Australia \\ Email: aazi@deakin.edu.au
}

Received February 2014

\begin{abstract}
Load frequency Control (LFC) is used for many years as part of Automatic Generation Control (AGC) in power system around the world. In a mixed power system, it is usual to find an area regulated by hydro generation interconnected to another area regulated by thermal generation or in combination of both. In the following study, performance of AGC for Thermal, Hydro and Thermal turbine based power system is examined, including how frequency bias setting influences AGC response and inadvertent interchange. Control performance analysis of three area interconnected systems is simulated and studied through Matlab Simulink software. Integral square error and Integral time absolute error has been used as performance criterion. It is shown that integral time absolute error (ITAE) as performance index leads to faster optimization of controller gain.
\end{abstract}

\section{Keywords}

Automatic Generation Control; Performance Index; ISE; ITAE; Discrete Controller

\section{Introduction}

Today's power system consists of control areas with many generating units with outputs that must be set according to economics. The analysis and design of Automatic Generation Control (AGC) system of individual generator eventually controlling large interconnections between different control areas play a vital role in automation of power system. The purposes of AGC are to maintain system frequency very close to a specified nominal value, to maintain generation of individual units' at the most economic value, to keep the correct value of tie-line power between different control areas. Automatic Generation Control (AGC) is defined by IEEE [1] as the regulation of the power output of electric generators within a prescribed area in response to changes in system frequency, tie-line loading, or the regulation of these to each other, so as to maintain the scheduled system frequency and/or the established interchange with other areas within predetermined limits. AGC has evolved rapidly from tie the time when the function was performed manually, through the days of analog systems to the present application of sophisticated direct digital control systems. The AGC problem has been extensively studied during the last four decades. Most of the work concentrates on the net interchange tie-line bias control strategy making use of the area control error (ACE). The existence of ACE means that there is excess or deficient of spinning stored energy in an area and a correction to stored energy is required to restore the system frequency to scheduled value. The early work on AGC has been reported by many authors. Cohn $[2,3]$ has exten- 
sively studied the static aspect of the net interchange tie line bias control strategy. On the static analysis basis Cohn has inferred that, for the minimum interaction between control areas, the frequency bias setting of a control area should be matched to the combined generation and load frequency response of the areas. However, no analysis has been made regarding deciding the magnitude of gain settings for the supplementary controllers. Concordia and Kirchmayer [4,5] have analyzed the AGC problem of two equal area, thermal-thermal, hydro-hydro and hydro-thermal systems, by simulating the systems differential equations. Although they have extensively studied the effect of variation of several parameters on the dynamic responses, no explicit methods have been proposed by them for optimization of controllers. Elgerd and Fosha [6] have used classical control theory (i.e.; integral of the squared error criterion) to optimize the integral controller gain setting. L. Works reported in literature on AGC pertains to either two-area thermal-thermal or hydro-hydro or combination of these two but there is no or very little work on AGC for multi-generation thermal-hydro system. In a mixed power system, it is usual to find an area regulated by hydro generation interconnected to another area regulated by thermal generation or in combination of both.

\section{Performance Index}

As known the design of a control system is an attempt to meet a set of specifications, which define the overall performance of the system in terms of certain measurable quantities. Furthermore, in adaptive control system schemes, the system parameters are automatically adjusted to keep the system at an optimum level of performance under varying inputs and varying conditions of operation. These systems require a performance index, which is a function of the variable system parameters. Extremum (minimum or maximum) value of this index then corresponds to the optimum set of parameters values. A number of such performance indices are used in practice, the most common being the Integral of the Squared Errors (ISE), given by Equation (1):

$$
\text { ISE }=\int_{0}^{\infty} \mathrm{e}^{2}(\mathrm{t}) \mathrm{dt}
$$

e (t)-> error considered.

This criterion, which has good mathematical track ability properties, penalizes positive and negative errors equally. It penalizes heavily on large errors; hence a small ISE usually results in a system with small overshoot. Since the integration is carried out over $(0, \infty)$; a small ISE limits the effect of small error lasting for long time and thus results in small settling time. Also a finite ISE implies that steady state error is zero. Minimization of ISE by adjusting system parameters is a good compromise between reduction of rise time to limit the effect of large initial error, reduction of peak overshoot and reduction of settling time to limit the effect of small error lasting for a long time. Another similar index is the integral of time multiplied by absolute error (ITAE) which exhibits the additional useful features that the initial large error (unavoidable for a step input) is not heavily weighted whereas errors that persist are heavily weighted. The ITAE performance index as given by Equation (2) has the advantages of producing smaller overshoots and oscillations than the ISE performance index.

$$
\operatorname{ITAE}=\int_{0}^{\infty} t\left|\mathrm{e}^{2}(\mathrm{t})\right| \mathrm{dt}
$$

e (t)-> error considered.

The performance indexes (PI) for this study are of the form as given in Equations (3) and (4):

$$
\begin{aligned}
& \text { ISE }=\int_{0}^{\infty}(\mathrm{ACE})^{2} \mathrm{dt} \\
& \text { ITAE }=\int_{0}^{\infty} \mathrm{t}|\mathrm{ACE}| \mathrm{dt}
\end{aligned}
$$

\section{System Investigated}

\subsection{Three Area Ring Interconnected System}

The sensitivity of any power plant depends upon the response time taken by the AGC to control the frequency 
change due to load variation of governor control. In the present work, considered power system is broken into three areas having one turbine generator model. The areas are connected by two tie lines with other two areas. The power flow over the transmission line will appear as summation of tie-line powers of two connected areas. The direction of flow will be dictated by the relative phase angle between the areas, which is determined by the relative speed deviations in the areas. Three areas interconnected in ring topology have been considered in this study (Figure 1).

For normal operation the power on the tie-line is given by Equation (4),

$$
\Delta \mathrm{P}_{12}=\frac{\left|\mathrm{V}_{1}^{0}\right|\left|\mathrm{V}_{2}^{0}\right|}{\mathrm{X}} \cos \left(\delta_{1}^{0}-\delta_{2}^{0}\right)\left(\Delta \delta_{1}-\Delta \delta_{2}\right) \mathrm{MW}
$$

where $\delta_{1}^{0}$ and $\delta_{2}^{0}$ are angles of end voltages $\mathrm{V}_{1}$ and $\mathrm{V}_{2}$ respectively and $\Delta \delta_{1}$ and $\Delta \delta_{2}$ is small deviation. We can define synchronizing coefficient as

$$
\mathrm{T}^{0}=\frac{\left|\mathrm{V}_{1}^{0}\right|\left|\mathrm{V}_{2}^{0}\right|}{\mathrm{X}} \cos \left(\delta_{1}^{0}-\delta_{2}^{0}\right) \mathrm{MW} / \mathrm{rad}
$$

The tie-line power deviation takes on the form

$$
\Delta \mathrm{P}_{12}=\mathrm{T}^{0}\left(\Delta \delta_{1}-\Delta \delta_{2}\right) \mathrm{MW}
$$

where,

$$
\Delta \delta=2 \prod \int^{\mathrm{t}} \Delta f \mathrm{dt} \mathrm{rad}
$$

By expressing tie-line power deviations in terms of $\Delta f$ rather than $\Delta \delta$, we get

$$
\mathrm{P}_{12}=\frac{2 \Pi \mathrm{T}^{0}}{\mathrm{~S}}\left(\Delta f_{1}(s)-\Delta f_{2}(s)\right) \mathrm{MW}
$$

Figure 2 shows the block diagram representation of interconnected power system consisting of three control areas consisting of thermal, hydro and thermal based power system without any controller implementation and integral controlled system is represented in Figure 3. Each control area is represented as consisting of a governor, turbine and generator block. Each control area is being fed a feedback in the form of speed droop. Respective tie-line powers are denoted using synchronizing coefficients.

\subsection{Integral Controlled Interconnected Power System}

The guiding principle in pool operation is that each area in normal steady-state should supply its own load and such portions of others load as had been agreed upon. It is required that the steady state tie-line power deviation following load changes must be brought to zero. This is accomplished by a single integrating block, but finding ACE as a linear combination of incremental frequency and incremental tie-line power accomplish this. The integrator output and thus the speed changer position, attains a constant value only when the frequency error has been reduced to zero. For pool operation, tie-line bias control is desired:

$$
\Delta \mathrm{P}_{\mathrm{ci}}(\mathrm{t})=-\mathrm{K}_{\mathrm{i}} \int\left(A C E_{i}\right) d t
$$

$$
\mathrm{ACE}_{\mathrm{i}}=\Delta \mathrm{P}_{\text {tiei }}(\mathrm{t})+\mathrm{b}_{\mathrm{i}} \Delta \mathrm{F}_{\mathrm{i}}, \mathrm{i}=1,2,3
$$

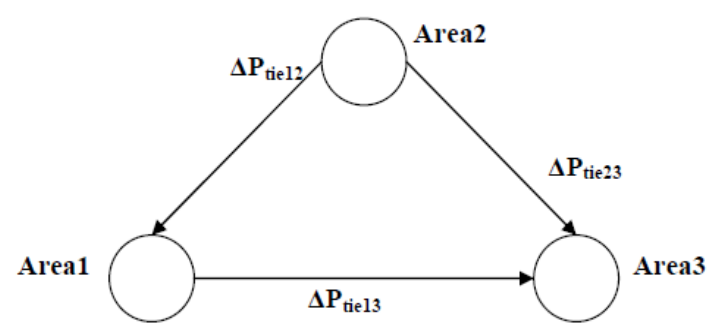

Figure 1. Ring topology connected three area model. 


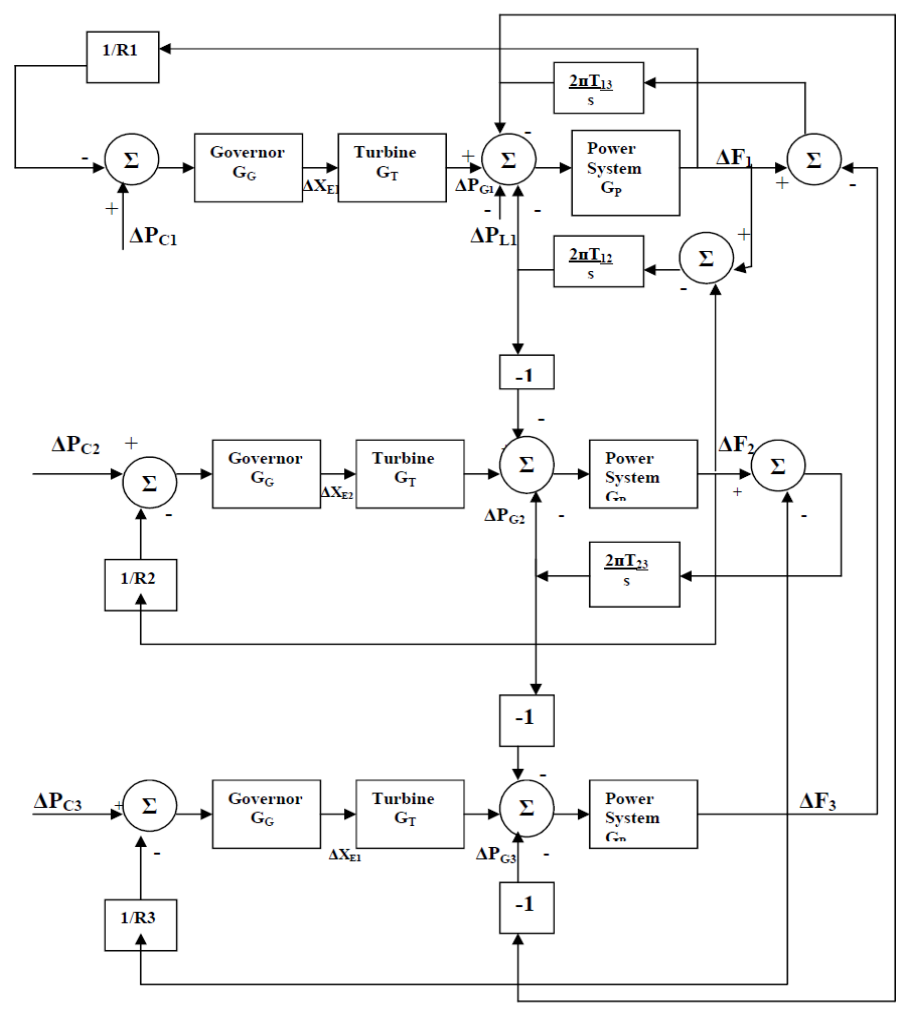

Figure 2. Uncontrolled Three Area Interconnected power system model.

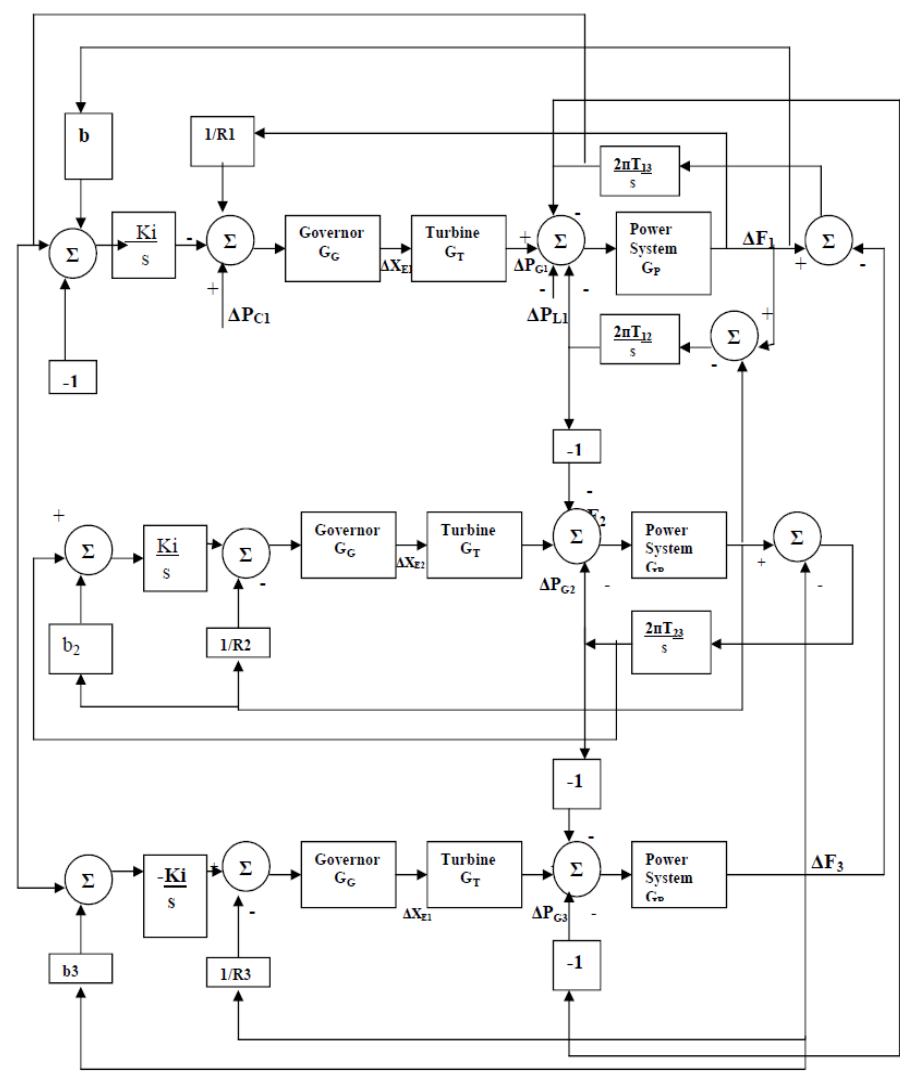

Figure 3. Controlled Three Area Interconnected power system model. 


$$
\Delta \mathrm{P}_{\text {tiei }}(\mathrm{t})=\mathrm{T}_{\mathrm{ij}}\left[\Delta \mathrm{F}_{\mathrm{i}}(\mathrm{t})-\Delta \mathrm{F}_{\mathrm{j}}(\mathrm{t})\right], \mathrm{i}, \mathrm{j}=1,2,3 . \mathrm{i} \neq \mathrm{j}
$$

$b_{i}$ is the frequency bias-settings, $K_{i}$ is the gain constant that controls the rate of integration and $\Delta \mathrm{P}_{c}$ is change in speed changer setting. In order to get the perfect adjustment of $\mathrm{P}_{\mathrm{ci}}$ we note that the frequency bias setting should be $b_{i}=\left(D_{i}+1 / R_{i}\right)$. In the steady state $A C E_{1}=A C E_{2}=A C E_{3}=0$, and also $\Delta f_{i}=0$. Figure 4 shows the block diagram representation of interconnected power system consisting of three control areas with integral controller implementation. So for good AGC design, the ACE signal should ideally be kept from becoming too large and it should not be allowed to drift i.e. the integral of ACE over an appropriate time should be small. The amount of control action called for by the AGC should be kept to a minimum.

\subsection{Discrete Controller}

A discrete control system as shown in Figure 5 [7,8] uses digital hardware, usually in the form of a programmed digital computer, as the heart of the controller. In contrast to analog controller, digital controller offers more advantages in terms of modifying its characteristics or of adapting the controller if plant dynamics change with operating conditions. In an interconnected power system, the system data (tie-line power change and frequency change etc.) are first sampled and then transferred over the telemetry link. The ACE signal is therefore available in the discrete form i.e. there occurs sampling operation between the system and the controller. The digital computer takes some time for data conversions and computations using some algorithm, there will always be a delay when a control law is implemented. The delay, which is called computational delay, degrades the control system performance. It should be minimized by proper choice of hardware and proper design of software for the control algorithm. Figure 5 shows the Simulink model of three area interconnected model for comparison of continuous controlled and discrete controlled optimum system.

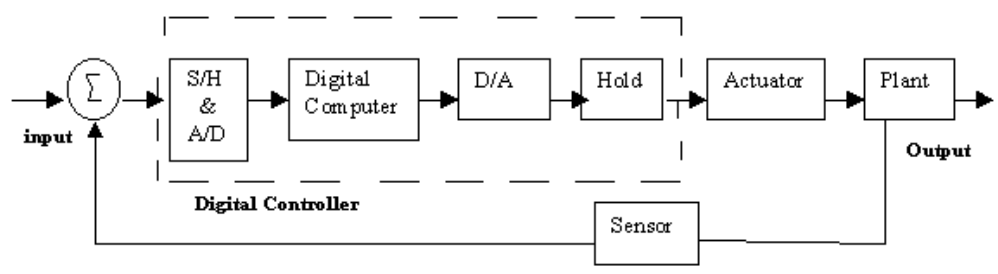

Figure 4. Digital/discrete control system.



Figure 5. Model for comparison of continuous and discrete controller performances. 


\section{Results}

\subsection{Dynamic Response of Three Area Thermal-Thermal-Thermal Uncontrolled System}

Simulink model of thermal-3 uncontrolled system is studied in terms of size variation besides transient performance of the system. $1000 \mathrm{Mw}$ is selected as base quantity and various parameters used in models are calculated on $1000 \mathrm{Mw}$ basis. The system is first considered as uncontrolled, i.e. no supplementary controllers are considered. $1 \%$ step load perturbation is given to one area. Frequency deviation and tie-line analysis shows that rating change has far less effect on system performance if control areas consist of same rating generators. As shown in Graphs 1-8, oscillations in terms of overshoot and undershoot produced on step unit change in load are low and settling time is also low. Settling time for frequency deviation and tie-line deviation stabilization is around 6 - 7 seconds for both systems with same and different ratings.

\subsection{Dynamic Response of Three Area Thermal-Thermal-Thermal Controlled System}

Dynamic study has been done on the basis of optimum integral gain constant. Model is studied in terms of size



Time, sec.

Graph 1. Change in frequency of area 1 w.r.t time (same ratings).

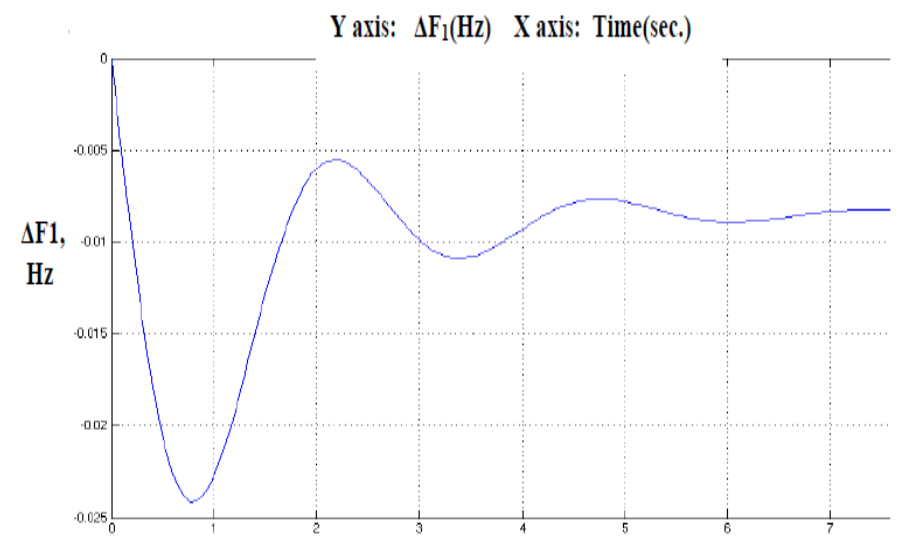

Time, sec.

Graph 2. Change in frequency of area 1 w.r.t time (different ratings). 


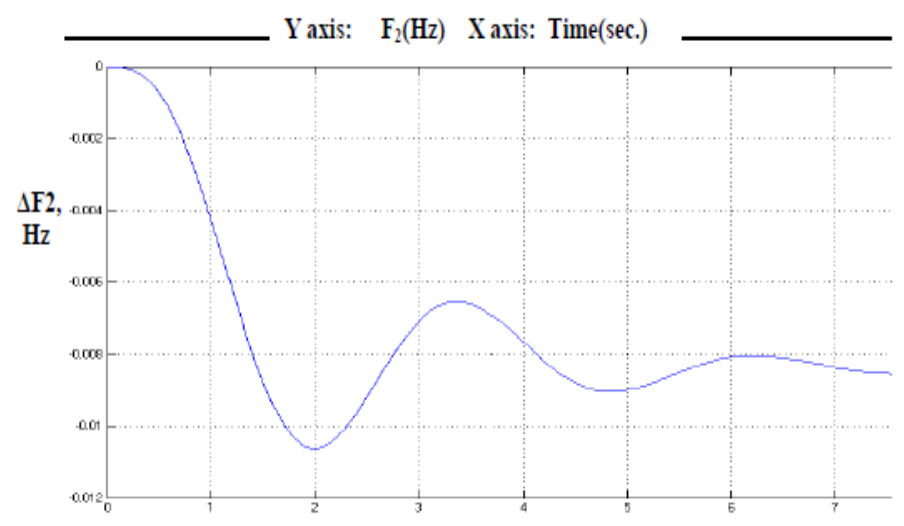

Time, sec.

Graph 3. Change in frequency of area 2 w.r.t time (same ratings).

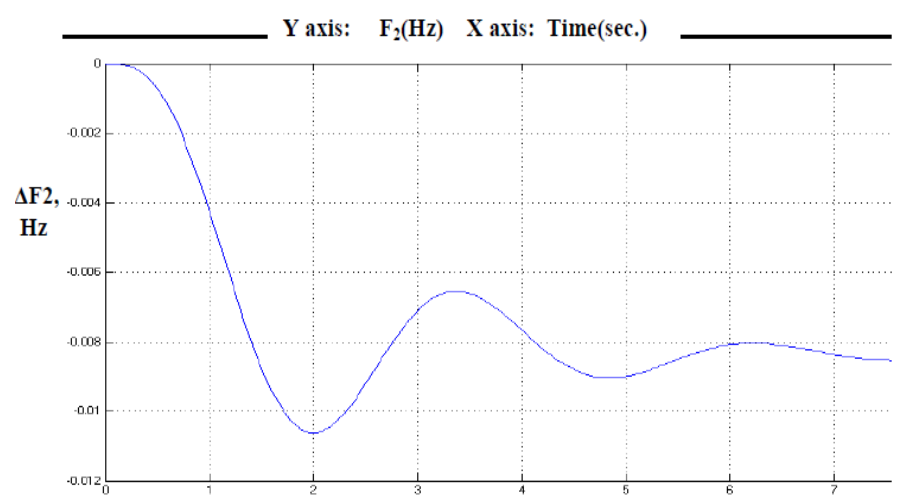

Time, sec.

Graph 4. Change in frequency of area 2 w.r.t time (different ratings).

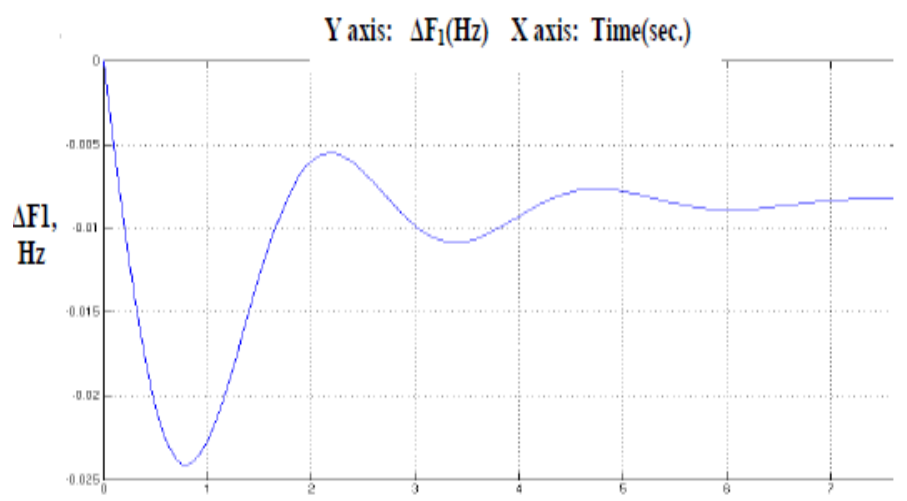

Time, sec.

Graph 5. Change in frequency of area 3 w.r.t time(same ratings). 


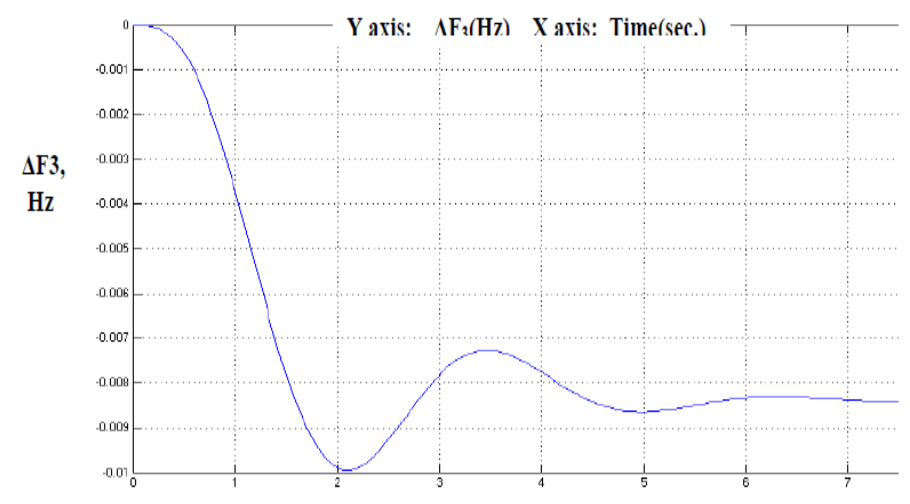

Time, sec.

Graph 6. Change in frequency of area 3 w.r.t time (different ratings).

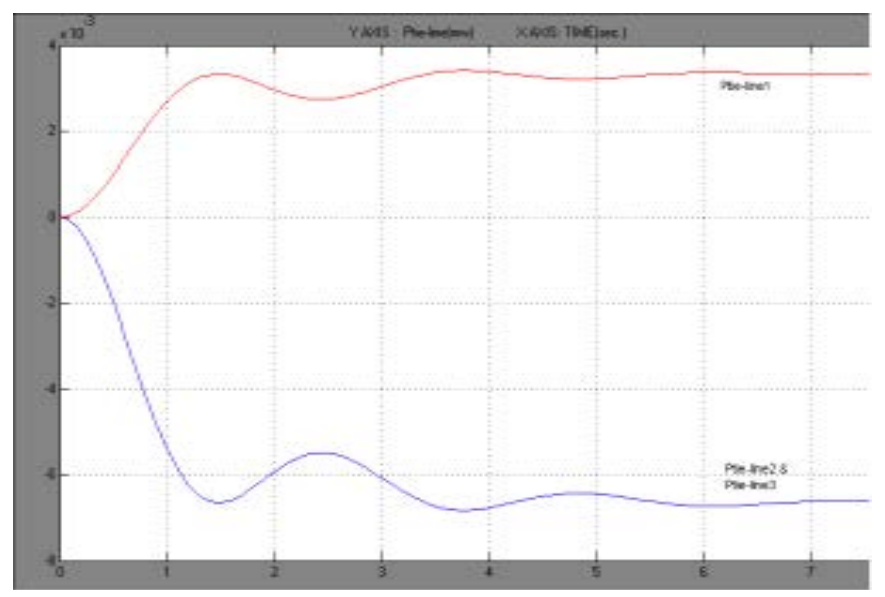

Graph 7. Change in Tie-line power w.r.t time (same ratings).

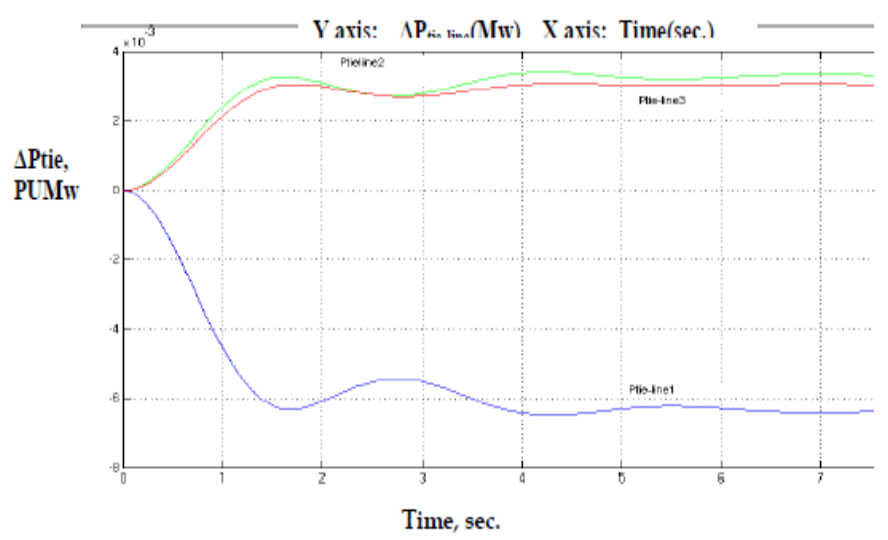

Graph 8. Change in Tie-line power w.r.t time (different ratings).

variation besides transient performance of the system. Oscillations in terms of overshoot and undershoot produced during initial period is comparatively more than uncontrolled area systems. As shown in Graphs 9-16, settling time for frequency deviation and tie-line deviation stabilization also varies for controlled system. Settling time is around 8 - 10 seconds for same rating systems and 20 - 30 seconds for different ratings. As depicted in Tables 1-4, faster optimized value is achieved by using ITAE than ISE. 


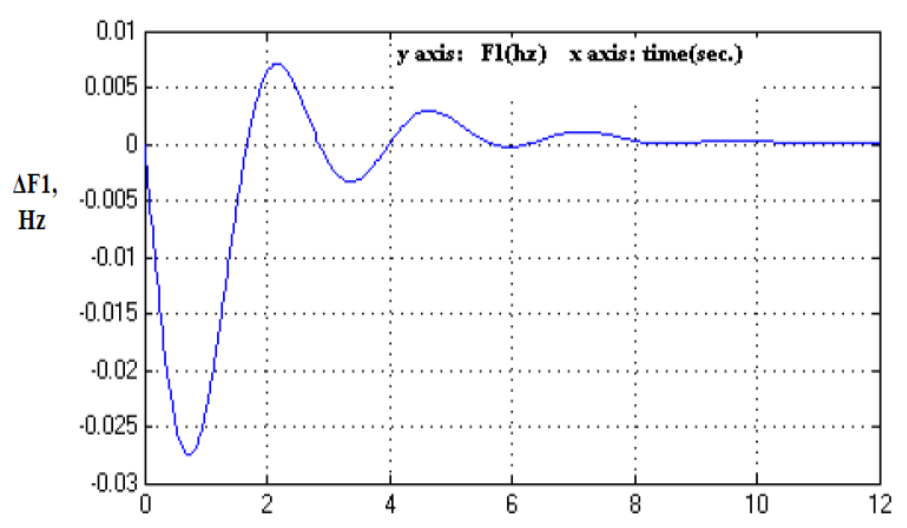

Time, sec.

Graph 9. Change in frequency of area 1 w.r.t time (same ratings).

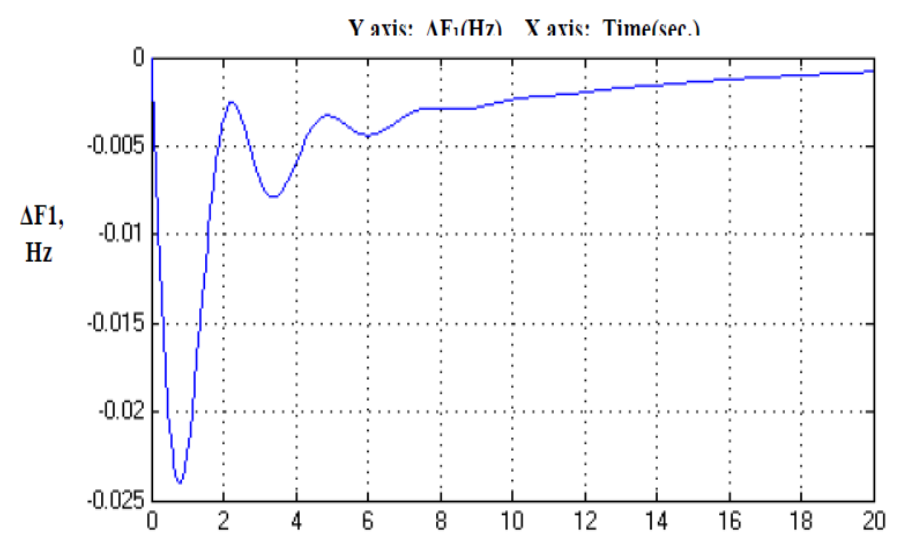

Time, sec.

Graph 10. Change in frequency of area 1 w.r.t time (different ratings).

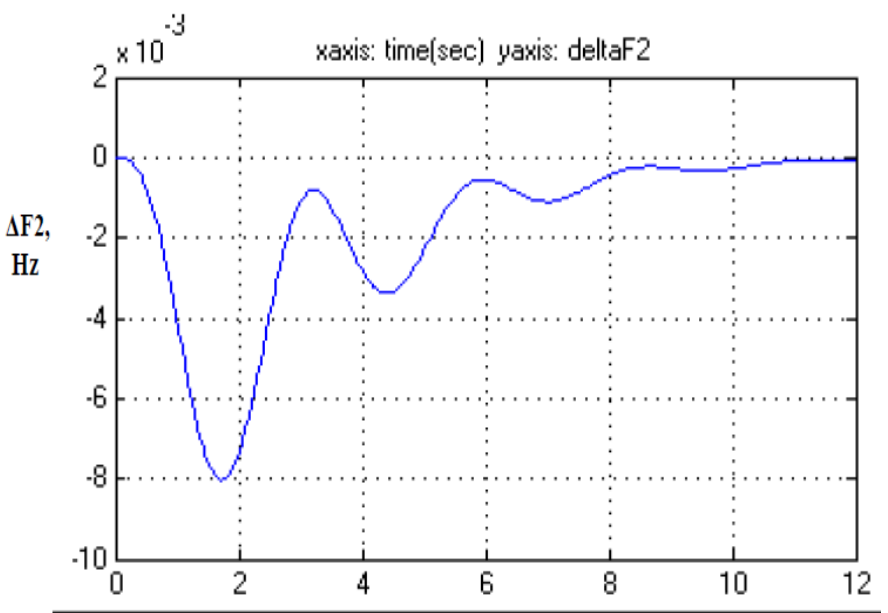

Time, sec.

Graph 11. Change in frequency of area 2 w.r.t time (same ratings). 


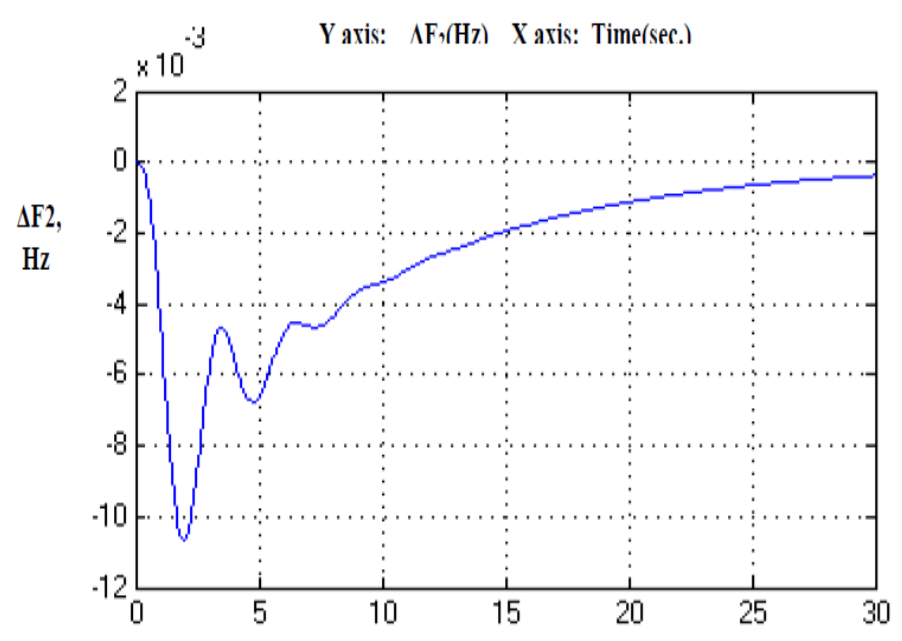

Time, sec.

Graph 12. Change in frequency of area 2 w.r.t time (different ratings).

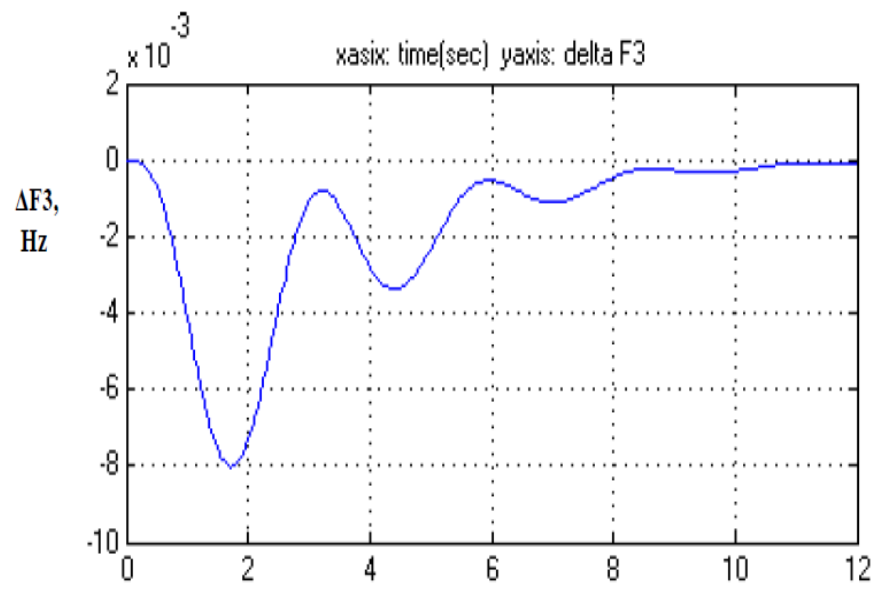

Graph 13. Change in frequency of area 3 w.r.t time (same ratings).



Graph 14. Change in frequency of area 3 w.r.t time (different ratings). 


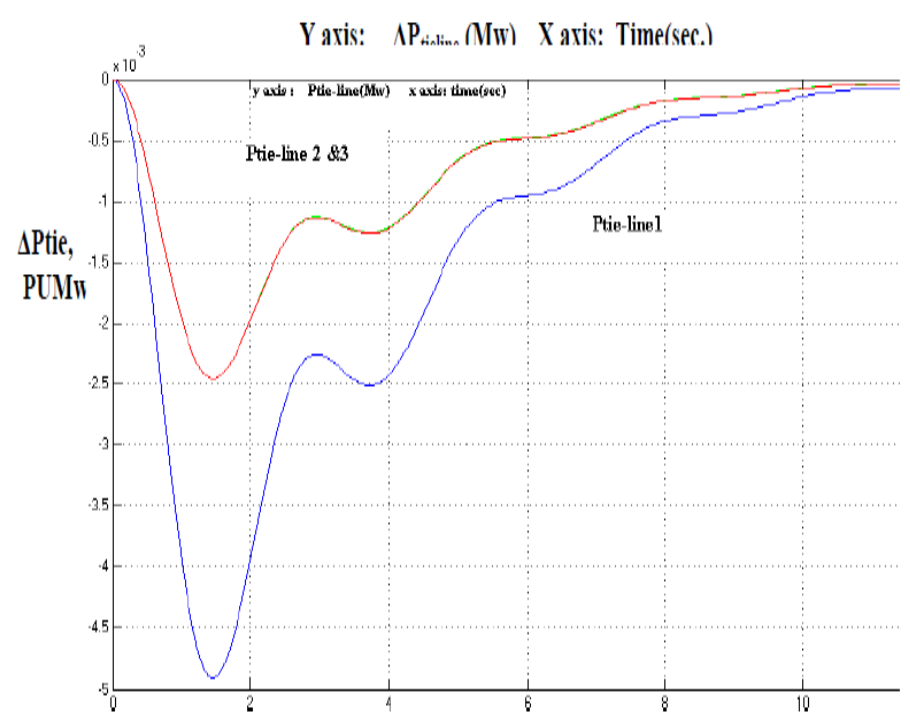

Time, sec.

Graph 15. Change in Tie-line power w.r.t time (same ratings).

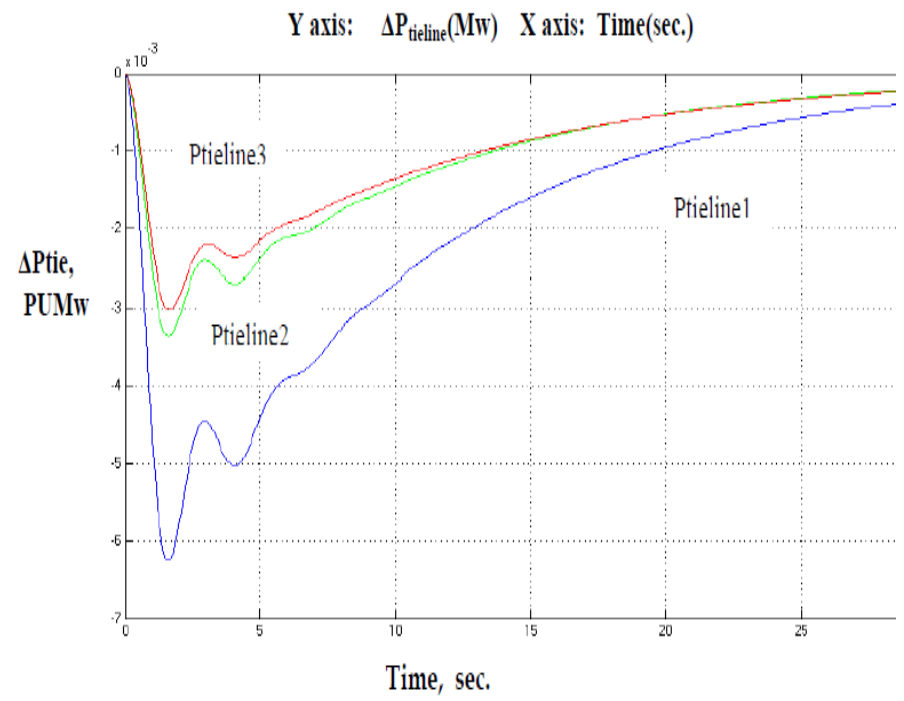

Graph 16. Change in Tie-line power w.r.t time (different ratings).

Table 1. Thermal-Thermal-Thermal model (same ratings) Performance index ISE, $\Delta \mathrm{P}_{\mathrm{D}}=0.01$.

\begin{tabular}{|c|c|c|c|c|}
\hline No. of Iterations & $\mathrm{K}_{\mathrm{i}}$ & $\operatorname{ISE} *(10)^{-4}$ & Optimum value of $\mathrm{K}_{\mathrm{i}}$ & Optimum value of $K_{D}$ \\
\hline & 0.2 & 2.315 & & \\
\hline \multirow[t]{4}{*}{$1^{\mathrm{st}}$} & 0.3 & 1.6462 & & \\
\hline & 0.1 & 4.2169 & & \\
\hline & & & 0.4 & 0.02 \\
\hline & 0.4 & 1.3186 & & \\
\hline \multirow[t]{2}{*}{$7^{\text {th }}$} & 0.4031 & 2.0824 & & \\
\hline & 0.3969 & 2.0969 & & \\
\hline
\end{tabular}


Table 2. Thermal-Thermal-Thermal model (Different ratings) Performance index ISE, $\Delta P_{D}=0.01$.

\begin{tabular}{|c|c|c|c|c|}
\hline No. of Iterations & $\mathrm{K}_{\mathrm{i}}$ & ISE * $(10)^{-4}$ & Optimum value of $K_{i}$ & Optimum value of $K_{D}$ \\
\hline & 0.25 & 1.9132 & \multirow{6}{*}{1.0} & \multirow{6}{*}{0.05} \\
\hline \multirow[t]{3}{*}{$1^{\text {st }}$} & 0.35 & 1.4577 & & \\
\hline & 0.45 & 2.2127 & & \\
\hline & 0.975 & 8.6565 & & \\
\hline \multirow[t]{2}{*}{$10^{\text {th }}$} & 1.0 & 8.6516 & & \\
\hline & 0.95 & 8.6565 & & \\
\hline
\end{tabular}

Table 3. Thermal-Thermal-Thermal model (same ratings) Performance index ITAE, $\Delta P_{D}=0.01$.

\begin{tabular}{|c|c|c|c|c|}
\hline No. of Iterations & $\mathrm{K}_{\mathrm{i}}$ & $\operatorname{ITAE} *(10)^{-4}$ & Optimum value of $\mathrm{K}_{\mathrm{i}}$ & Optimum value of $\mathrm{K}_{\mathrm{D}}$ \\
\hline \multirow{3}{*}{$1 \mathrm{st}$} & 0.3 & 2.4361 & \multirow{6}{*}{0.625} & \multirow{6}{*}{0.03125} \\
\hline & 0.4 & 2.0896 & & \\
\hline & 0.2 & 3.2128 & & \\
\hline \multirow{3}{*}{ 6th } & 0.65 & 1.8635 & & \\
\hline & 0.675 & 1.8695 & & \\
\hline & 0.625 & 1.8619 & & \\
\hline
\end{tabular}

Table 4. Thermal-Thermal-Thermal model (Different ratings) Performance index ITAE, $\Delta \mathrm{P}_{\mathrm{D}}=0.01$.

\begin{tabular}{ccccc}
\hline No. of Iterations & $\mathrm{K}_{\mathrm{i}}$ & ITAE & Optimum value of $\mathrm{K}_{\mathrm{i}}$ & Optimum value of $\mathrm{K}_{\mathrm{D}}$ \\
\hline & 0.2 & 1.0632 & & \\
$1^{\text {st }}$ & 0.3 & 0.7509 & & \\
& 0.1 & 1.8197 & 0.4938 & \\
& 0.5 & 0.5406 & \\
$8^{\text {th }}$ & 0.5063 & 0.541 & \\
& 0.4938 & 0.5406 & \\
\hline
\end{tabular}

\subsection{Dynamic Response of Thermal-Hydro-Thermal Uncontrolled Power System}

Oscillations in terms of overshoot and undershoot produced on step unit change in load are much than thermal-3 system and settling time has also increased, as shown in Graphs 17-24. Settling time for frequency deviation stabilization is around 10-15 seconds for both systems with same and different ratings. There is a wide variation in individual transient responses of control areas when per unit load disturbance is produced in any 1 area.

\subsection{Dynamic Response of Thermal-Hydro-Thermal Controlled Power System}

Referring Graphs 25-32, oscillations in terms of overshoot and undershoot produced during initial period is comparatively more than uncontrolled area systems and it is varying with system rating change. With optimum controller gain, settling time is achieved in around 10 - 17 seconds. Settling time is around 10 - 17 seconds for same rating systems and 15 - 20 seconds for different ratings. A wide fluctuation in tie-line powers is observed with maximum undershoot in tie-line 1 and maximum overshoot in tie-line 3. As shown in Tables 5-8, ITAE gives fast optimized value in comparison to ISE. 


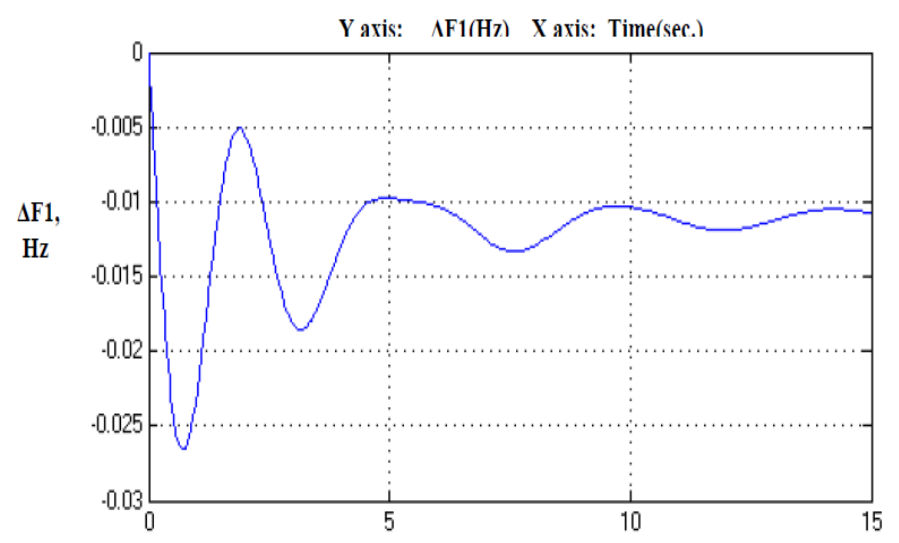

Time, sec.

Graph 17. Change in frequency of area 1 w.r.t time (different ratings).

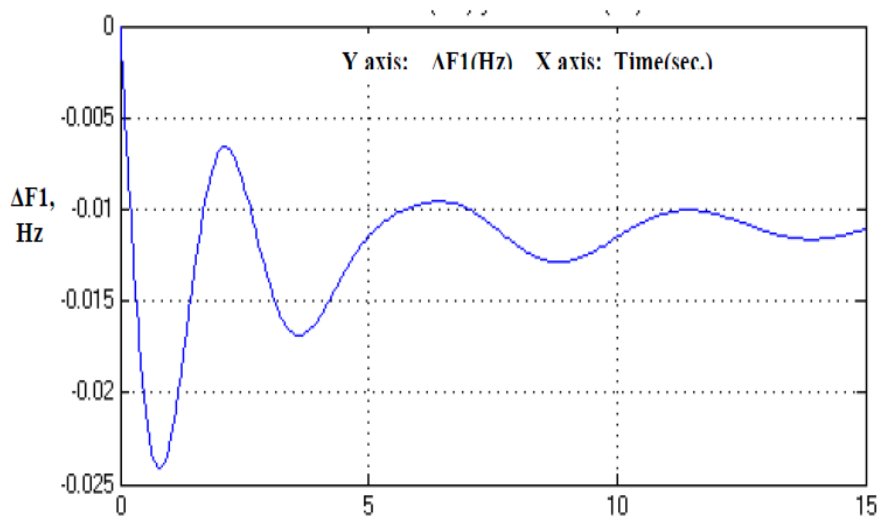

Time, sec.

Graph 18. Change in frequency of area 1 w.r.t time (same ratings).

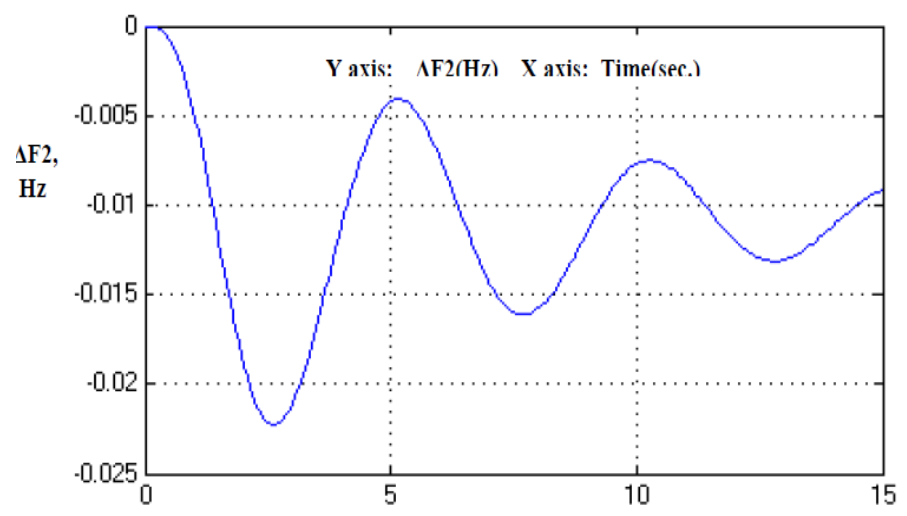

Time, sec.

Graph 19. Change in frequency of area 2 w.r.t time (different ratings). 


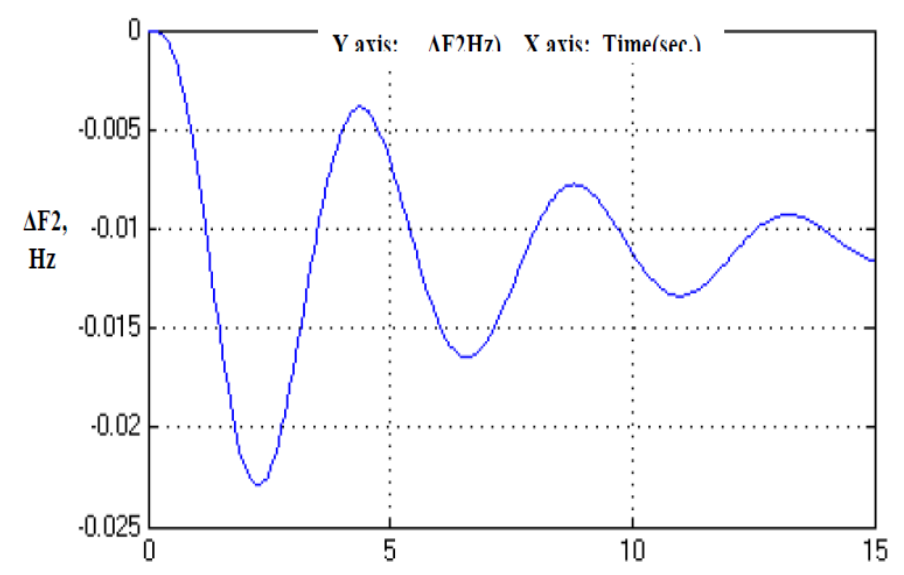

Time, sec.

Graph 20. Change in frequency of area 2 w.r.t time (same ratings).

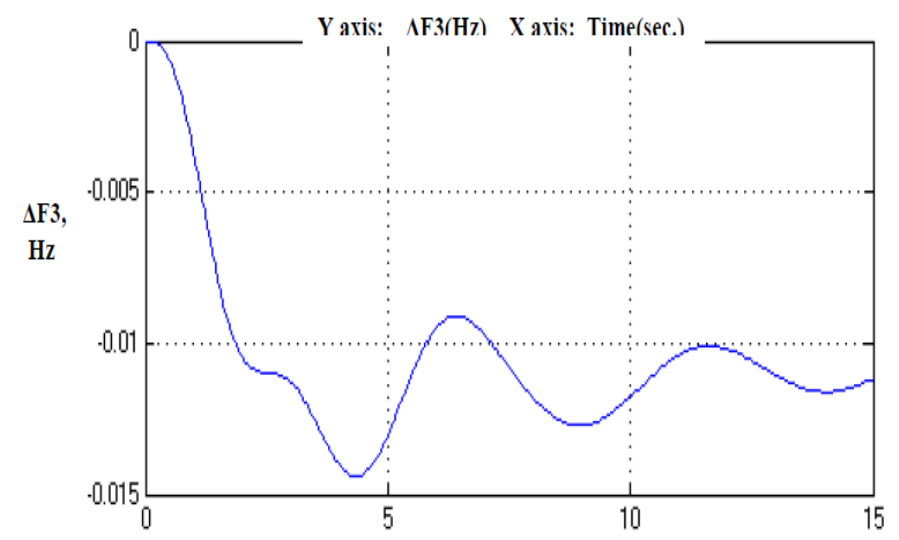

Time, sec.

Graph 21. Change in frequency of area 3 w.r.t time (different ratings).

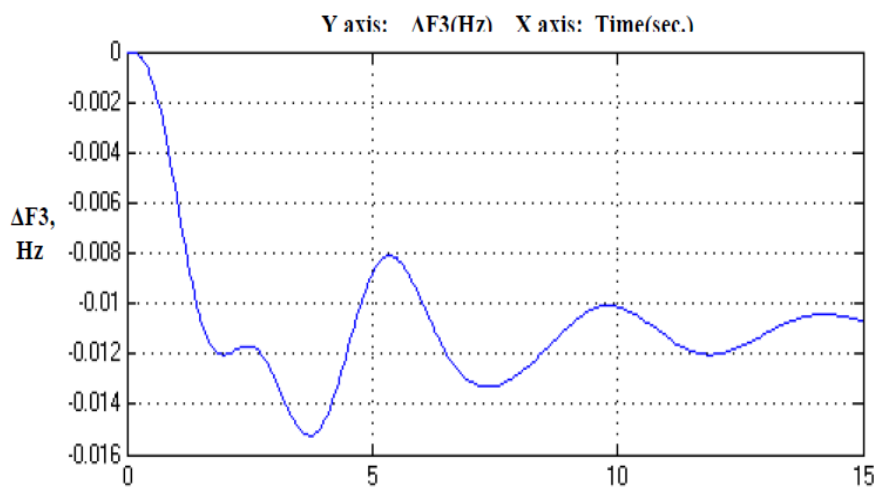

Time, sec.

Graph 22. Change in frequency of area 3 w.r.t time (same ratings). 




Time, sec.

Graph 23. Change in Tie-line power w.r.t time (different ratings).

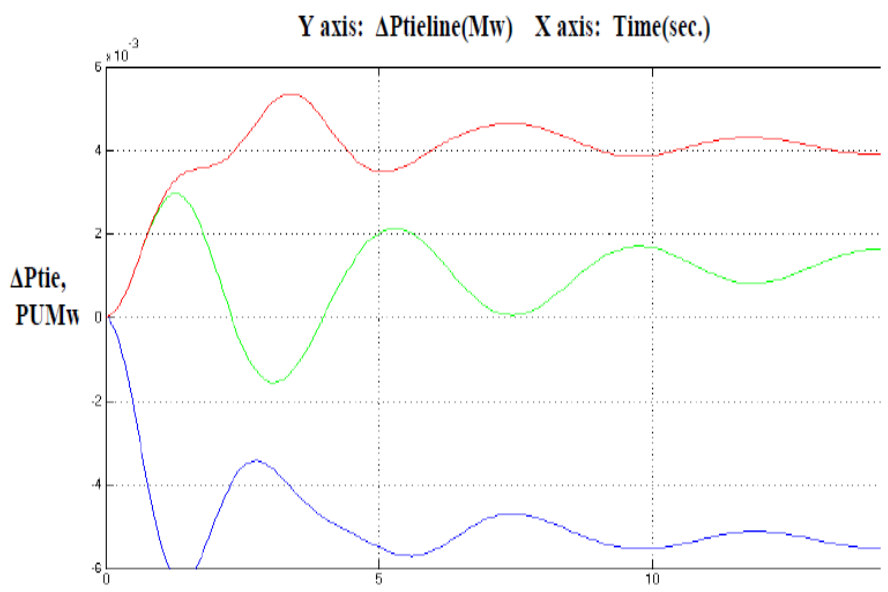

Time, sec.

Graph 24. Change in Tie-line power w.r.t time (same ratings).

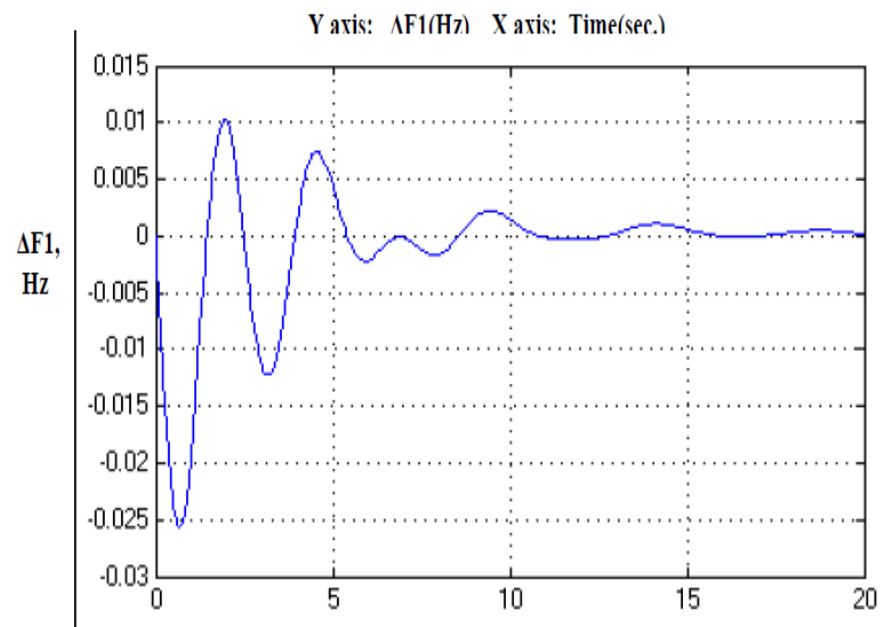

Time, sec.

Graph 25. Change in frequency of area 1 w.r.t time (same ratings). 




Time, sec.

Graph 26. Change in frequency of area 1 w.r.t time (different ratings).

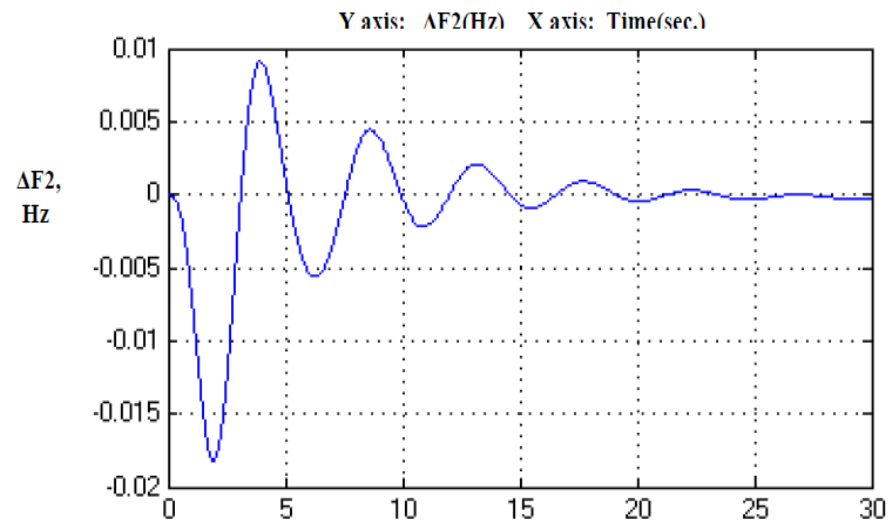

Time, sec.

Graph 27. Change in frequency of area 2 w.r.t time (same ratings).

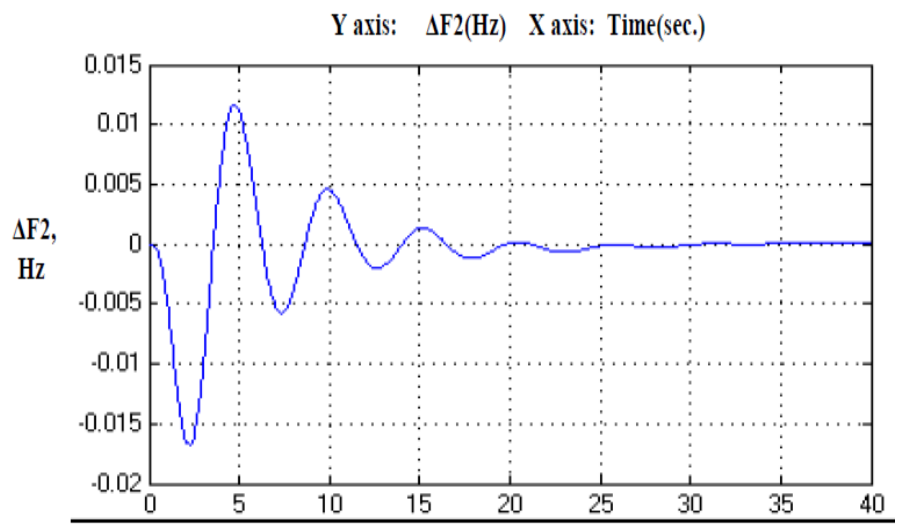

Time, sec.

Graph 28. Change in frequency of area 2 w.r.t time (different ratings). 


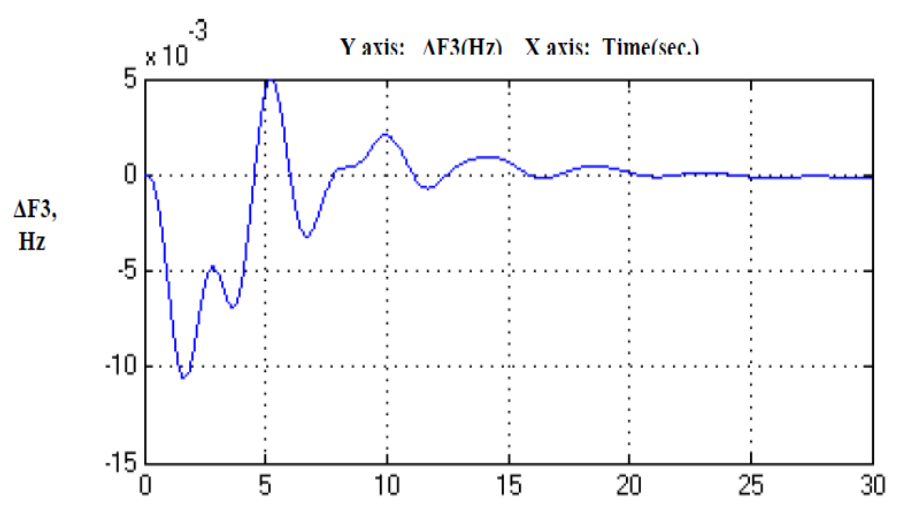

Time, sec.

Graph 29. Change in frequency of area 3 w.r.t time (same ratings).



Time, sec.

Graph 30. Change in frequency of area 3 w.r.t time (different ratings).

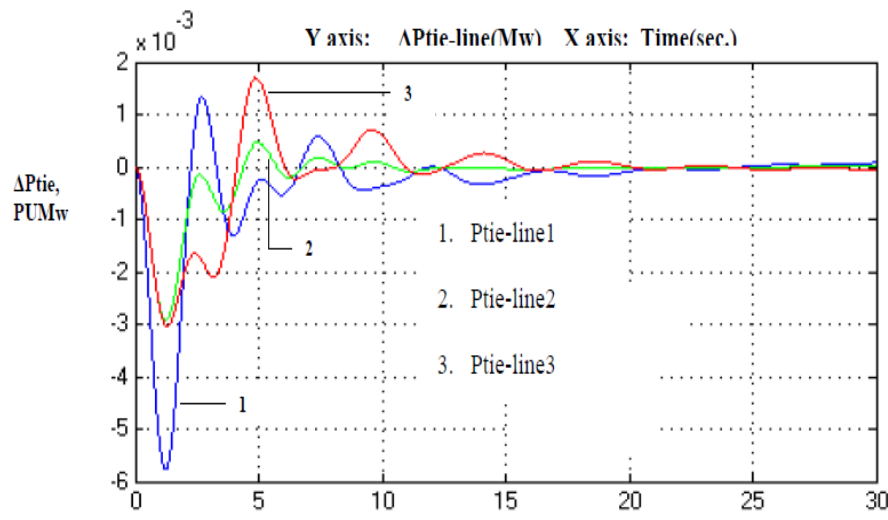

Time, sec.

Graph 31. Change in Tie-line power w.r.t time (same ratings). 




Graph 32. Change in Tie-line power w.r.t time (different ratings).

Table 5. Thermal-Hydro-Thermal model (same ratings) Performance index ISE, $\Delta \mathrm{P}_{\mathrm{D}}=0.01$.

\begin{tabular}{ccccc}
\hline No. of Iterations & $\mathrm{K}_{\mathrm{i}}$ & ISE $^{*}(10)^{-4}$ & Optimum value of $\mathrm{K}_{\mathrm{i}}$ & Optimum value of $\mathrm{K}_{\mathrm{D}}$ \\
\hline & 0.1 & 7.1105 & & \\
$1^{\text {st }}$ & 0.2 & 4.3643 & & \\
& 0.3 & 3.5163 & 0.5203 & \\
& 0.529 & 3.0901 & \\
\hline
\end{tabular}

Table 6. Thermal-Hydro-Thermal model (Different ratings) Performance index ISE, $\Delta P_{D}=0.01$.

\begin{tabular}{|c|c|c|c|c|}
\hline No. of Iterations & $\mathrm{K}_{\mathrm{i}}$ & $\operatorname{ISE}^{*}(10)^{-4}$ & Optimum value of $\mathrm{K}_{\mathrm{i}}$ & Optimum value of $K_{D}$ \\
\hline \multirow{3}{*}{$1^{\mathrm{st}}$} & 0.1 & 6.8518 & \multirow{6}{*}{0.557} & \multirow{6}{*}{0.02785} \\
\hline & 0.2 & 401401 & & \\
\hline & 0.3 & 302881 & & \\
\hline \multirow{3}{*}{$15^{\text {th }}$} & 0.5578 & 2.7613 & & \\
\hline & 05586 & 2.7613 & & \\
\hline & 0.557 & 2.7613 & & \\
\hline
\end{tabular}

Table 7. Thermal-Hydro-Thermal model (same ratings) Performance index ITAE, $\Delta \mathrm{P}_{\mathrm{D}}=0.01$.

\begin{tabular}{ccccc}
\hline No. of Iterations & $\mathrm{K}_{\mathrm{i}}$ & ITAE & Optimum value of $\mathrm{K}_{\mathrm{i}}$ & Optimum value of $\mathrm{K}_{\mathrm{D}}$ \\
\hline & 0.3 & 3.5154 & \\
$1^{\text {st }}$ & 0.4 & 3.1783 & & \\
& 0.2 & 4.3643 & 0.525 & \\
& 0.525 & 3.0557 & \\
$7^{\text {th }}$ & 0.5315 & 3.0561 & \\
\hline
\end{tabular}


Table 8. Thermal-Hydro-Thermal model (Different ratings) Performance index ITAE, $\Delta P_{D}=0.01$.

\begin{tabular}{|c|c|c|c|c|}
\hline No. of Iterations & $\mathrm{K}_{\mathrm{i}}$ & ITAE & Optimum value of $\mathrm{K}_{\mathrm{i}}$ & Optimum value of $K_{D}$ \\
\hline & 0.3 & 1.9487 & & \\
\hline \multirow[t]{4}{*}{$1^{\mathrm{st}}$} & 0.4 & 1.7327 & & \\
\hline & 0.2 & 2.5543 & & \\
\hline & & & 0.4688 & 0.02344 \\
\hline & 0.4688 & 1.699 & & \\
\hline \multirow[t]{2}{*}{$10^{\text {th }}$} & 0.4719 & 1.6991 & & \\
\hline & 0.4656 & 1.6991 & & \\
\hline
\end{tabular}

\subsection{Comparison of Three Area Thermal-Hydro-Thermal Continuous and Discrete Controlled System}

$1000 \mathrm{Mw}$ is selected as base quantity. Dynamic study has been done on the basis of optimum integral gain constant. Continuous type and its discrete version have been used in the model. Sample time of 0.05 sec satisfying nequist criterion has been utilized in discrete model. Thermal-hydro-thermal model is studied in terms of size variation besides transient performance of the system. Optimum controller gain \& stabilizing time for frequency deviation and tie-line deviation stabilization varies for discrete and continuous controlled system. Referring Graphs 33-38, it can be seen that discrete controller takes longer time for stabilizing deviations. Oscillations produced after discrete controller are much more than continuous controlled system. Settling time increases by 5 - 10 seconds for all combinations of systems but preferable viewing discrete nature of power system data. With optimum controller gain, stabilizing time for frequency deviation and tie-line deviation stabilization varies largely for discretely controlled system. Initial oscillations in terms of overshoot \& undershoot are more for discrete controlled systems.

\section{Conclusions}

When there is sudden load change in any interconnected area, the frequency and tie-line power are affected. It is essential to minimize these errors for economic and reliable operation of power system. So the integral controller is studied here to meet the stated demand. Integral square error and integral time absolute error has been considered as performance indices in this study. Controller designed here minimizes the change in frequency in all the three area. Change in tie line power should also be minimized because if there is any load change in any area, then the extra power required can be got from the other area but for this tie line should be capable of transmitting this extra power but as the agreement done by the systems tie-line has a pre specified capacity, so the control action should take place in area where the change has occurred to keep the change in tie-line power minimum. So for this change in tie-line power is also considered in performance index. It has been found out that integral time square error (ITAE), if utilized as performance index rather than Integral of squared error, produces fast optimized value of integral gain. It is further observed that reduction of $\mathrm{R}$ (speed droop) reduces frequency error. With high R, low damping of oscillations is produced \& low R, high damping of oscillations is produced. Use of subcritical gain setting gives sluggish non oscillatory response of control loop which means integral of $\Delta f(\mathrm{t})$ and time error is relatively large. If all parameters are considered same, then freq. Drop will be $1 / 3^{\text {rd }}$ of that which would be experience if the control areas were operating alone.

A comparison of both continuous and discrete controller performance is done for the system. It is observed that hydro based system takes much longer time for stabilization in comparison to others. Fast oscillations in terms of overshoot and undershoot are observed in a mixed system consisting of thermal and hydro based generation for a step unit disturbance in load. Discrete controller takes longer time for stabilization in comparison to continuous type controlled system but is preferred in view of discrete nature of power system data.

As we all know for a good power system economic consideration is an important factor but the controller designed in this project does not meet the requirement of economic load dispatch which is an important aspect of 


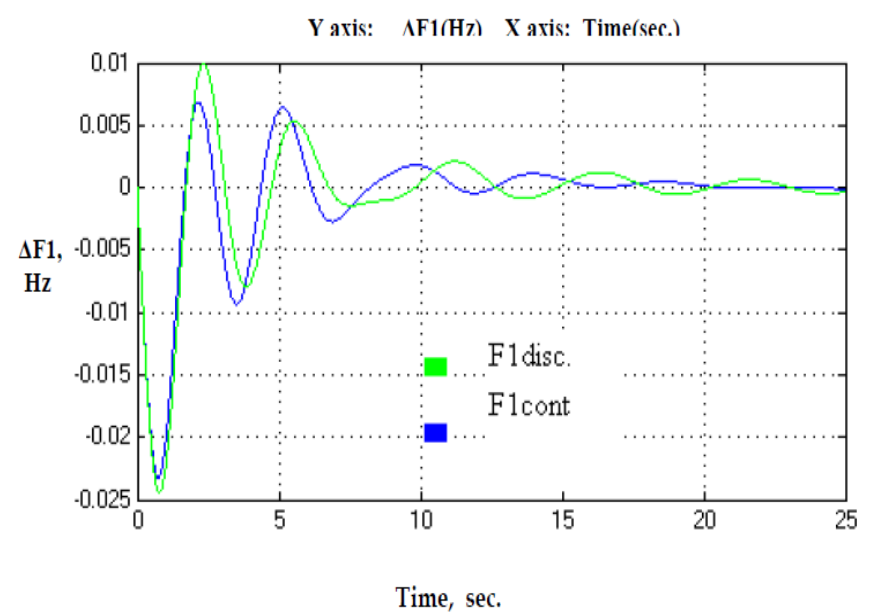

Graph 33. Change in frequency of area 1 w.r.t time.

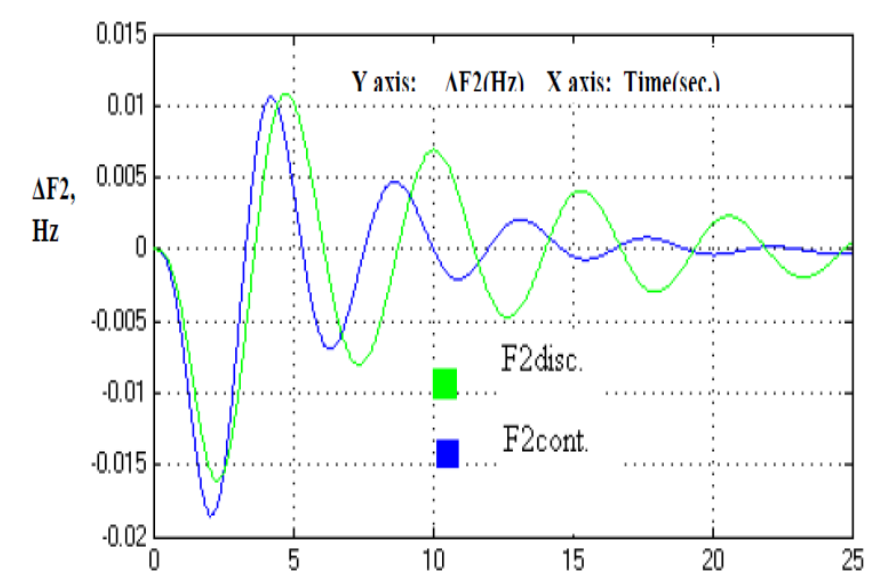

Time, sec.

Graph 34. Change in frequency of area 2 w.r.t time.

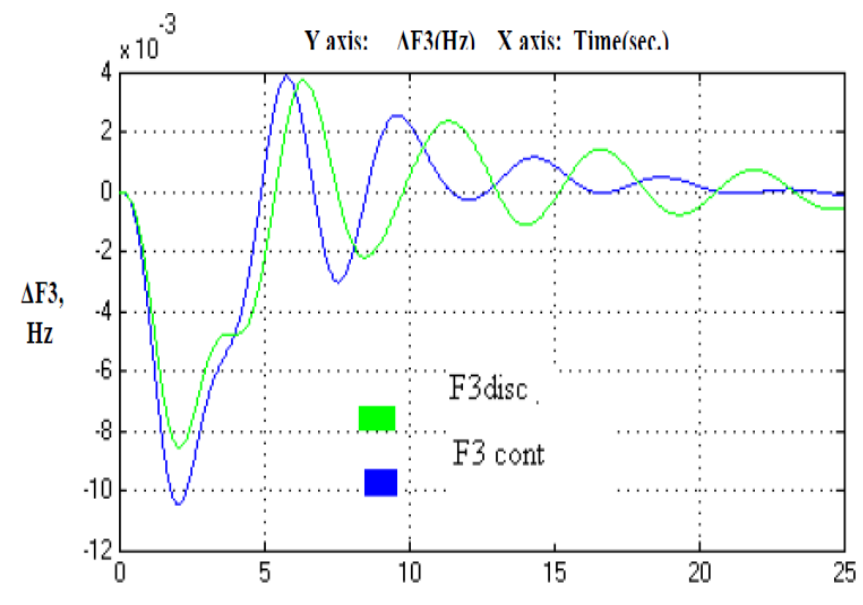

Time, sec.

Graph 35. Change in frequency of area 3 w.r.t time. 


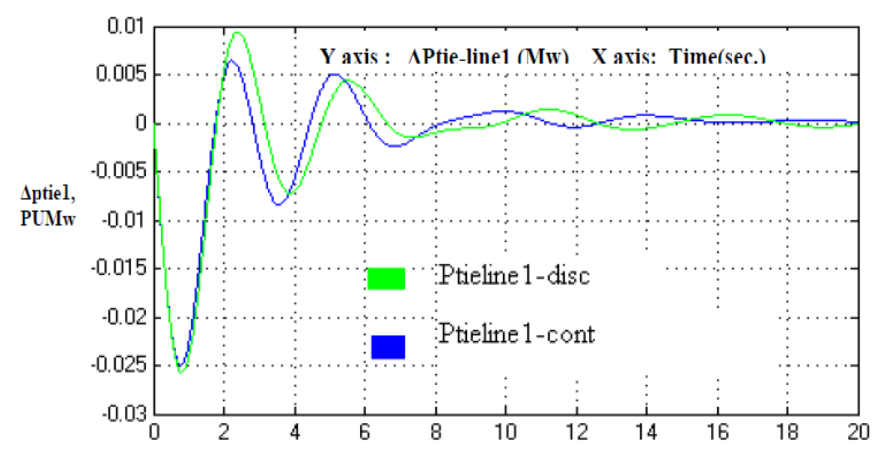

Time, sec.

Graph 36. Change in tie-line 1 power w.r.t time.



Graph 37. Change in tie-line 2 power w.r.t time.

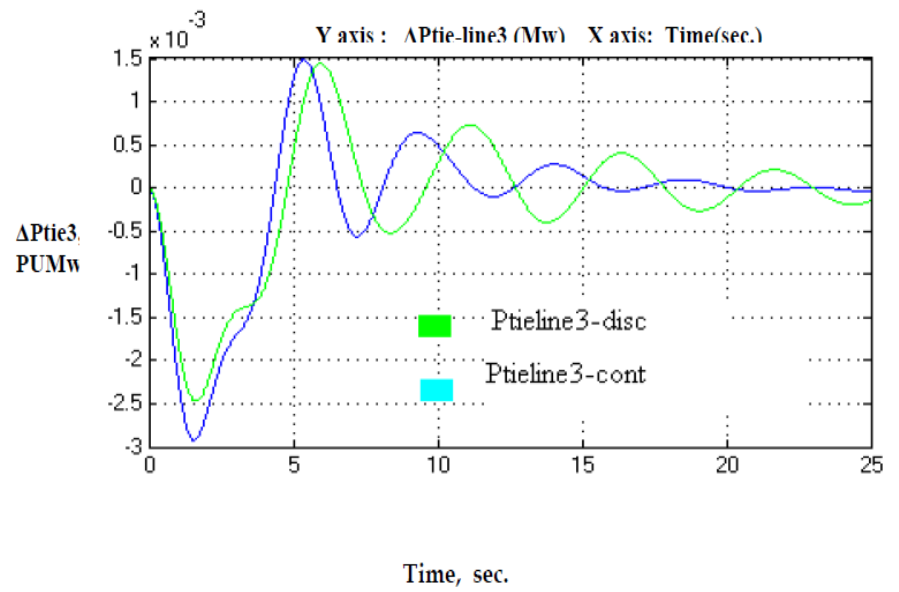

Graph 38. Change in tie-line 3 power w.r.t time.

AGC. So, economic dispatch problem can be further studied for multi generation type system. More dynamic models can be used in the study. e.g. turbine governor models with non-linearity introduced in them can be studied. 


\section{References}

[1] IEEE Committee Report (1970) IEEE Standard Definitions of Terms for Automatic Generation Control of Electric Power System. IEEE Transactions on Power Apparatus and Systems, PAS-89, 1358-1364.

[2] Cohn, N. (1957) Some Aspects of Tie-Line Bias Control on Interconnected Power Systems. AIEE Transactions, 75, $1415-1436$.

[3] Cohn, N. (1950) Power Flow Control Basic Concepts for Interconnected Systems. Electric Light and Power, 28, 82-92.

[4] Concordia, G. and Kirchmayer, L.K. (1953) Tie-Line Power and Frequency Control of Power System. AIEE Transactions, 72, 562-572.

[5] Kirchmayer, L.K. (1959) Economic Control of Interconnected Systems. Wiley, 35-47.

[6] Elgerd, O.I. (1971) Electric Energy System Theory: An Introduction. McGraw Hill, 315-389.

[7] Gopal, M. (2003) Digital Control and State Variable Methods. Tata McGraw Hill.

[8] Dorf, R.C. and Bishop, R.H. (1998) Modern Control Systems. 8th Edition, Pearson Education, Inc.

\section{Symbols Used}

$\Delta \mathrm{F}_{\mathrm{S}} \quad$ System frequency deviation. $\mathrm{Hz}$

$\mathrm{R} \quad$ Sped regulation of generator

$\mathrm{K}_{\mathrm{G}} \quad$ Gain of speed governor

$\mathrm{T}_{\mathrm{G}} \quad$ Time constant of speed governor

$\mathrm{T}_{\mathrm{T}} \quad$ Time constant of thermal turbine

$\Delta \mathrm{P}_{\mathrm{G}} \quad$ Change in generated power

$\Delta \mathrm{P}_{\mathrm{D}} \quad$ Change in load demand

$\triangle \mathrm{Pc} \quad$ Change in speed governor

$\mathrm{T}_{\mathrm{P}} \quad$ Power system time constant

$\mathrm{K}_{\mathrm{P}} \quad$ Power system gain

$\Delta \mathrm{P}_{\text {tie }} \quad$ Tie-line power deviations

$\mathrm{T}_{\mathrm{ij}} \quad$ Synchronizing coefficient for tie-line

$\mathrm{Ki}$ Integral controller gain

$\mathrm{K}_{\mathrm{Di}} \quad$ Discrete integral controller gain

ACE Area Controller error

B Bias constant

ISE Integral square error

ITAE Integral time absolute error

Ts Sampling period

i Area index

$\mathrm{j} \quad$ Area index 